Arias, J. D, et al. (2020). Aproximaciones contextuales sobre el devenir de las revistas contables colombianas. Perspectivas plurales de los editores. Contaduría Universidad de Antioquia, 77, 131-165.

Doi: https://doi.org/10.17533/udea.rc.n77a05

\title{
Aproximaciones contextuales sobre el devenir de las revistas contables colombianas. Perspectivas plurales de los editores
}

\author{
Juan David Arias Suárez (Compilador) \\ jd.arias@hotmail.com \\ Politécnico Grancolombiano - Asfacop \\ Orcid: 0000-0002-4218-953X
}

Fernando Salazar (Pontificia Universidad Javeriana) Jaime Andrés Correa-García (Universidad de Antioquia) Michael Andrés Diaz (Universidad Santo Tomás) Héctor José Sarmiento (Politécnico Colombiano Jaime Isaza Cadavid) Jane Andrew (The University of Sydney) Christine Cooper (University of Edinburgh) Yves Gendron (Université Laval)

Laura C. Acosta, Daniel S. Malaver, Víctor M. Castañeda (Universidad Nacional de Colombia)

Yuliana Gómez (Tecnológico de Antioquia) Luisa Fernanda Giraldo (Universidad de Manizales) Julieth Sorany Alzate (Universidad Autónoma Latinoamericana) Marisleidy Alba (Universidad Externado de Colombia) José Joaquín Ortiz (Universidad Libre de Colombia) David Andrés Camargo (Universidad Militar Nueva Granada) 
Aproximaciones contextuales sobre el devenir de las revistas contables colombianas. Perspectivas plurales de los editores

Resumen: Este artículo presenta perspectivas plurales y contextuales sobre el devenir de las revistas contables colombianas, desde las letras y voces directas de quienes conviven cotidianamente con la labor editorial. Como una aproximación reflexiva, 13 editores de revistas especializadas en contabilidad y disciplinas conexas presentan argumentos a favor y en contra de los temas más recurrentes en las publicaciones cientificas actuales, como el modelo de evaluación de impacto a través de citas, la interacción de la comunidad académica disciplinar, las tendencias de las políticas públicas de ciencia, tecnología e innovación y el sentido de la investigación. Con una discusión respetuosa, diversa, sincera y vinculante, el artículo no presenta posiciones unánimes e invita a ampliar la conversación en diferentes espacios académicos para que la comunidad contable comprenda el origen y el sentido de las tendencias, estructuras y aspectos de calidad e impacto que recaen sobre las publicaciones cientificas.

Palabras clave: Contabilidad, revistas cientificas, medición de impacto, comunidad académica.

Contextual approximations on the evolution of Colombian accounting journals. Plural perspectives from editors

Abstract: This paper presents plural and contextual perspectives on the evolution of Colombian accounting journals, from the direct writing and voices of those who are daily involved with the editorial job. As a reflective approximation, 13 editors from journals specialized in accounting and connected disciplines present arguments in favor and against the most recurrent topics in current scientific publications, such as the citation-based impact assessment model, interaction with the disciplinary academic community, trends in science, technology and innovation public policies, and the sense of research. Through a respectful, diverse, sincere and linking discussion, the paper does not present unanimous positions and invites to broaden dialog in different academic spaces so that the accounting community understands the origin and sense of the trends, structures, and quality and impact aspects affecting scientific publications.

Keywords: Accounting, scientific journals, impact measurement, academic community.

Aproximações contextuais sobre o futuro das revistas de contabilidade colombianas. perspetivas plurais dos editores

Resumo: Este artigo apresenta perspectivas plurais e contextuais sobre o futuro das revistas de contabilidade colombianas, desde as letras e vozes diretas de quem convivem cotidianamente com a labor editorial. Como uma abordagem reflexiva, 13 editores de revistas especializadas em contabilidade e disciplinas afins apresentam argumentos a favor e contra os assuntos mais recorrentes nas publicações científicas atuais, como o padrão de avaliação de impacto por meio de citações, a interação da comunidade acadêmica disciplinar, as tendências das políticas públicas de ciência, tecnologia e inovação e o significado da pesquisa. Com uma discussão respeitosa, diversa, sincera e vinculante, o artigo não apresenta posições unânimes e convida a ampliar a conversação em diferentes espaços acadêmicos para que a comunidade contábil compreenda a origem e o significado das tendências, estruturas e aspectos de qualidade e impacto que recaem sobre as publicações cientificas.

Palavras chave: Contabilidade, revistas cientificas, medição de impacto, comunidade acadêmica.

Des approximations contextuelles sur le devenir des revues comptables colombiennes. Perspectives plurielles des éditeurs

Résumé: Cette étude presente des perspectives plurielles et contextuelles sur le devenir des revues comptables colombiennes, au moyen de lettres et de voix de ce qui coexistent au quotidien avec le travail editorial. À titre d'approche réfléchie, 13 éditeurs de revues spécialisées en comptabilité et disciplines connexes avancent des arguments pour et contre les thèmes les plus récurrents dans les publications scientifiques actuelles, comme le modèle d'évaluation d'impact par citation, l'interaction de la communauté universitaire disciplinaire, les tendances des politiques publiques en matière de science, de technologie et d'innovation et le sens de la recherche. En faisant appel à une discussion respectueuse, diverse, sincère et contraignante, cet article ne présente pas des positions unanimes et invite à élargir la conversation dans différents espaces académiques pour que la communauté comptable comprenne l'origine et le sens des tendances, structures et aspects de qualité et d'impact sur les publications scientifiques.

Mots-clés: Comptabilité, revues scientifiques, mesure d'impact, communauté académique. 
Cont. udea (julio-diciembre), pp. 131-165. (C) Universidad de Antioquia-2020.

\title{
Aproximaciones contextuales sobre el devenir de las revistas contables colombianas. Perspectivas plurales de los editores
}

\author{
Juan David Arias Suárez (Compilador). \\ https://doi.org/10.17533/udea.rc.n77a05
}

Primera versión recibida en junio de 2020 - Versión final aceptada en septiembre de 2020

\section{Introducción}

En Colombia la dinámica actual de las publicaciones científicas de áreas Ecomo la contabilidad y disciplinas afines ha venido transformándose en las últimas décadas debido a las presiones institucionales de las políticas de Ciencia, Tecnología e Innovación de Publindex-Minciencias y sus formas de medición sobre la calidad e impacto de las revistas científicas. La producción de conocimiento ha tenido un viraje intencional hacia espacios limitados y esquivos para las reflexiones y aportes hispanoparlantes y latinoamericanos como lo son WoS, Scopus y el Book Citation Index, donde élites académicas tienen el poder de visibilizar e invisibilizar las publicaciones de acuerdo con sus representaciones sobre ciencia, calidad e impacto, debido a las asimetrías de citación propias de las categorías sociológicas y epistémicas anglo-eurocéntricas de la relación norte-sur.

El posicionamiento de perspectivas mayoritariamente cuantitativas en las publicaciones de la disciplina contable, como elemento propio de las revistas escalafonadas internacionalmente, ha dejado escuetos, pero no menores espacios para las corrientes heterodoxas, interpretativas, críticas, decoloniales y latinoamericanistas en contabilidad que es necesario divulgar, y para trabajos locales de aportes específicos a comunidades singulares. La pluralidad intelectual, diversidad epistémica y aportes colectivos son atomizados por métricas sesgadas del impacto social del conocimiento, las formas cognoscitivas del saber contable, su interdisciplinariedad, sus mediaciones socio-históricas y su ethos. 
Arias, J. D., et al. Aproximaciones contextuales sobre el devenir de las revistas contables colombianas...

El futuro de las revistas contables colombianas es incierto; la mayoría de las publicaciones nacionales han avanzado en rigurosidad, oportunidad, calidad e indexaciones, pero en ese proceso, muchas revistas han perecido y otras trabajan más por su sostenimiento que por su avance. Aun así, la comunidad académica continúa valorando la producción nacional, la tradición epistémica y la construcción de comunidades. Artículos y debates de este tipo han sido construidos otrora en Macías (2012; 2013), Macías, et al. (2014), Gómez-Villegas (2012; 2013), Rueda (2012) y continuados en algunas editoriales de revistas: León (2015), Macías, (2017), Camargo (2018a), Sarmiento (2018), Arias (2018), Malaver (2018), Sánchez (2019) y Gómez-Zapata (2019).

En este orden de ideas, y con el ánimo de dar continuidad a las discusiones previas, surge este artículo como un espacio para la reflexión plural e interinstitucional, respetuosa, pero sincera y crítica, convocada por la Red Colombiana de Editores y Revistas Contables (Reditores) para dar a conocer a la comunidad académica contable, las sensaciones, preocupaciones, retos y la heterogeneidad de posiciones desde la perspectiva de trece editores de revistas especializadas en contabilidad o cuyos espacios de publicación interdisciplinar en ciencias económicas, sostienen una sección activa sobre investigaciones y reflexiones contables. En esa vía, este documento está compuesto por esta breve introducción contextual, aunada a la estructura metodológica; luego se presenta el aporte de cada editor a la discusión convocada y finalmente se genera un espacio sintético de discusión donde se destacan las principales posiciones, incertidumbres, puntos de encuentro y de desencuentro.

\section{Estructura metodológica}

A partir de las reflexiones y argumentos suscitados en el pasado IV Encuentro Nacional de Editores Contables, organizado en agosto de 2019 por Reditores, Asfacop y la Universidad Externado de Colombia, se lograron establecer los dos focos de discusión más constantes sobre el devenir de las revistas contables:

1. Discrepancias sobre el modelo de medición de impacto a través de citas y el reconocimiento de métricas alternativas. Posicionamiento, rankings, y lucro sobre los procesos de publicación. ¿Las métricas inducen a la eliminación o unificación de las revistas colombianas de contabilidad?

2. Participación de las revistas nacionales en discusiones disciplinares internacionales.

Prácticas editoriales novedosas y tensiones sobre las publicaciones en inglés.

De esa forma, se convocó a los editores de revistas integrantes y no integrantes de Reditores para generar disertaciones, discusiones y propuestas alrededor de estos dos tópicos. Sin restar rigor académico, la construcción de este documento tiene una finalidad reflexiva y comunicativa, y promotora de acciones posteriores. Así, este artículo debe ser visto como un punto 
de partida, pues la idea es utilizarlo como base argumental para debates posteriores en el marco de documentos y eventos nacionales donde participen las revistas, y para forjar un constante diálogo escrito entre las voces editoriales que derive en acciones para la comunidad.

Las razones anteriores, aunadas a la necesidad de maduración de la comunidad académica nacional y latinoamericana, a la construcción de identidad propia y a la protección de las revistas nacionales, permitió establecer esta convocatoria, plural, incluyente y vinculante, con ánimo de que las revistas se relacionen como pares y se fomenten espacios de cooperación entre las revistas contables colombianas. Las revistas y los editores participantes se presentan a continuación, cuya presentación fue establecida por estricto orden de aparición en el texto:

Tabla 1: Autores por revista e institución

\begin{tabular}{|c|c|c|}
\hline Revista & Autores-Editores & Institución \\
\hline Cuadernos de Contabilidad & Fernando Salazar & Pontificia Universidad Javeriana \\
\hline $\begin{array}{l}\text { Contaduría Universidad de } \\
\text { Antioquia }\end{array}$ & Jaime Andrés Correa-García & Universidad de Antioquia \\
\hline Activos & Michael Andrés Díaz & Universidad Santo Tomás \\
\hline Teuken Bidikay & Héctor José Sarmiento & $\begin{array}{l}\text { Politécnico Colombiano } \\
\text { Jaime Isaza Cadavid }\end{array}$ \\
\hline $\begin{array}{l}\text { Critical Perspectives } \\
\text { on Accounting }^{1}\end{array}$ & $\begin{array}{l}\text { Jane Andrew, Christine Cooper, } \\
\text { Yves Gendron }\end{array}$ & Academic Press Inc. - Elsevier \\
\hline Innovar & $\begin{array}{l}\text { Laura C. Acosta, Daniel S. Malaver, } \\
\text { Víctor M. Castañeda }\end{array}$ & Universidad Nacional de Colombia \\
\hline En-contexto & Yuliana Gómez & Tecnológico de Antioquia \\
\hline $\begin{array}{l}\text { Revista Colombiana } \\
\text { de Contabilidad }\end{array}$ & Juan David Arias & $\begin{array}{l}\text { Asociación Colombiana de Facultades de } \\
\text { Contaduría Pública }\end{array}$ \\
\hline Lúmina & Luisa Fernanda Giraldo & Universidad de Manizales \\
\hline Visión Contable & Julieth Sorany Alzate & Universidad Autónoma Latinoamericana \\
\hline Apuntes Contables & Marisleidy Alba & Universidad Externado de Colombia \\
\hline Criterio Libre & José Joaquín Ortiz & Universidad Libre de Colombia \\
\hline $\begin{array}{l}\text { Revista Facultad } \\
\text { de Ciencias Económicas }\end{array}$ & David Andrés Camargo & Universidad Militar Nueva Granada \\
\hline
\end{tabular}

Fuente: Elaboración propia.

1 La revista CPA participa como única publicación no-colombiana en calidad de invitada por Reditores, debido a sus recientes discusiones sobre las asimetrías idiomáticas en las publicaciones (Andrew, Cooper y Gendron, 2020) y la necesaria interacción y relacionamiento con otras publicaciones. 
Arias, J. D., et al. Aproximaciones contextuales sobre el devenir de las revistas contables colombianas...

Este documento no tiene una metodología de investigación precisa, diferente a una dialéctica argumental entre los autores. Para el espacio de discusión sobre los puntos planteados se establecieron las siguientes categorías analíticas:

(A). Modelo de evaluación de impacto

(B). Interacción de una comunidad académica (nacional e internacional)

(C). Política pública de Ciencia, Tecnología e Innovación

(D). Sentido de la investigación

Para operacionalizar la disertación argumental de cada editor, se plantearon relaciones entre las taxonomías establecidas, para presentar algunas discusiones temáticas sobre las relaciones entre cada categoría de forma secuencial. Posterior a estas discusiones relacionales se presentan algunas consideraciones generales sobre los principales focos de discusión y sobre el futuro de las publicaciones en contabilidad, derivadas del debate suscitado. Este espacio final no representa la convergencia de los editores, sino las perspectivas conclusivas del compilador.

Es importante hacer hincapié en que este texto no es una rúbrica cerrada, unidimensional o doctrinal sobre una forma de ver las publicaciones contables. Se destaca que no hay posiciones unánimes sobre cada tema y que la versión final del documento fue aprobada por todos los editores participantes.

\section{Aportes Editores}

\section{III.I. Fernando Salazar - Cuadernos de Contabilidad}

En la actualidad, era de digitalización tecnológica con las llamadas revolución 4.0 y 5.0 que está ingresando desde Japón, se aprecia un proceso de aceleración en el desarrollo teórico y práctico de la Contabilidad, la que debe responder a las necesidades de la sociedad tecnológica desde la gestión avanzada, perfilándose como nueva herramienta de generación de ventajas competitivas desde el punto de vista empresarial. Ahora se puede mencionar que la contabilidad financiera ha dejado de jugar un papel importante para la dirección de la empresa, más allá de la aportación realizada desde el marco normativo. La información que se genera, en muchas ocasiones es utilizada para las decisiones externas de estas organizaciones. Por otro lado, la contabilidad de costos ha sido utilizada en sus inicios para la valoración de los bienes y servicios. En cualquier caso, las dos áreas de aplicación de las ciencias contables tienen una serie de limitaciones a la hora de enfrentarse a la problemática que hoy plantean las nuevas tecnologías de la información para esta ciencia. Para Ripoll (2012), la transferencia de resultados de investigación tiene como misión apoyar y suscitar la transferencia de los resultados de investigación desarrollados por las universidades y otros centros o instituciones 
a las empresas y demás agentes socioeconómicos. Con ello, se contribuye al desarrollo y consolidación, en el entorno universitario, de la "Función Transferencia de Conocimiento". Los estudios de ciencia, tecnología y sociedad (CTS) constituyen una diversidad de programas de colaboración interdisciplinar y hoy día transdisciplinar que, enfatizando la dimensión social de la ciencia y la tecnología, comparten: (a) el rechazo de la imagen de la ciencia como una actividad pura; (b) la crítica de la concepción de la tecnología como ciencia aplicada y neutral; y (c) la condena de la tecnocracia (López Cerezo, 2001).

Abordando el tema desde la perspectiva de las publicaciones, investigación y proceso editorial en las ciencias contables, en sus diferentes líneas de investigación, el establecimiento como disciplina académica en las últimas décadas ha hecho que se incremente la credibilidad y el estado de este campo del conocimiento (Baldvinsdottir, Mitchell y Norreklit, 2010). Este período, ha desencadenado un aumento de investigaciones en contabilidad de gestión y en la teoría o teorías que sustentan la investigación (Ittner y Larcker, 2001, 2002; Zimmerman, 2001; Hopwood, 2002; Lukka y Mouritsen, 2002, Luft y Shields, 2002; Chapman, Hopwood y Shields, 2007; Malmi y Granlund, 2009; Vaivio y Sirén, 2010; Modell, 2010; Lukka, 2010; Merchant, 2010), centradas en los preceptos básicos, teorías centrales (economía, sociología, etc.), enfoques (decisión o control), y métodos de exploración (descriptivo o normativo).

Es importante identificar y analizar los temas estudiados y la coherencia de los métodos de investigación aplicados, debido a la existencia de un número limitado de revistas con un enfoque específico. De esta forma se abren nuevos debates que promueven el desarrollo científico de las ciencias contables. Si bien, como en todas las profesiones, la del investigador en general y en particular, la del investigador en ciencias contables, está sujeta a presiones, entre ellas, cobra relevancia el hecho de publicar artículos en revistas indexadas, por afectar a numerosas facetas en la trayectoria de un investigador, como las decisiones de ocupación y promociones, reputación o importe de compensación económica. En este sentido, Bonner Hesford, Van y Young (2006), Chan (2009), destacan que la publicación en las principales revistas del campo de investigación, miden no solo la calidad de investigación de un académico-investigador, sino también su productividad, al considerar el número de artículos publicados en ellas, la indexación, cuartil y nivel de indexación, siendo las más importantes Scopus y WoS. 
Arias, J. D., et al. Aproximaciones contextuales sobre el devenir de las revistas contables colombianas...

\section{III.II. Jaime Andrés Correa-García - Contaduría Universidad de Antioquia}

El debate creciente a nivel internacional sobre la relevancia de las publicaciones académicas, la necesidad de ralentizar la velocidad de publicación y en general a no entrar desaforadamente en la carrera del "publish or perish", ha llegado a Colombia y a la disciplina contable en un momento en que se evidencia una mayor calidad, variedad y profundidad de las investigaciones contables, producto entre otras razones de la mayor cantidad de doctores ( $\mathrm{PhD})$ dedicados a la investigación contable. Es así como Macías (2019) reflexiona sobre el aporte de este nivel de formación a la comunidad contable colombiana y augura para el futuro cercano la inserción en las discusiones internacionales en la frontera del conocimiento contable. En este orden de ideas, se evidencia una masa crítica creciente de investigadores contables en Colombia que no necesariamente discurren por la línea de investigación predominante en Colombia que ha sido orientada a la epistemología y teoría contable. Por lo anterior, resulta contradictorio pensar que se busca una inserción paulatina en espacios de debate internacional, sin eufemismos, publicar en revistas internacionales de alto impacto por sus indicadores en JCR o Scopus y por otro lado no pensar necesariamente en el impacto de las publicaciones, en las citas o en el capital relacional que pueda derivarse de estas publicaciones.

El valor de las publicaciones científicas no radica en la cantidad de las citas y el tipo de revistas donde se es citado. Sin embargo, no deja de ser un factor que da cuenta de la relevancia de un texto y de los nexos que puede lograr con las comunidades académicas nacional e internacional. Pretender que la citación es el fin es un error, considerarla como un acto de vanidad del investigador por si solo molesta, pero entendida como un mecanismo para el establecimiento de redes de investigación y comunicación entre las revistas e investigadores le otorga valor, esto más allá de las críticas por la irrelevancia de algunas citas o su superficialidad (Wakefield, 2008). Son múltiples los factores que inciden en la cantidad de citaciones, los cuales pueden ser universalistas o particularistas como la alta reputación del autor o el prestigio de la institución (Meyer, Waldkirch, Duscher y Just, 2018). No obstante, las críticas arrecian en Colombia, principalmente porque en la disciplina contable ha habido una preponderancia hacia la epistemología y teoría contable de corte nacionalista. Así mismo Meyer et al. (2018) presenta críticas a las citaciones como mecanismos para determinar el impacto de las revistas en contabilidad al igual que sucede en otras áreas del conocimiento. También hay que entender que algunas de los principales aportes no se han evidenciado en revistas (Griffith, Cavusgil y Xu, 2008) y los rankings internacionales tienden a ignorarlos. 
Con estos dos escenarios descritos para la investigación contable en Colombia: 1) Una creciente y dinámica de un segmento de la comunidad contable que empieza a trascender la tradicional corriente centrada en los estudios teóricos y reflexivos, y 2) Un ambiente casi que hostil para la publicación en revistas de alto impacto (que se centran principalmente en las citaciones), la pregunta que viene a la reflexión es, ¿Nos marginamos? El debate actual es interesante y llega en un punto de inflexión de la investigación contable en Colombia, donde algunos de los principales investigadores "juegan a dos bandas", de un lado criticando el modelo y de otro publicando en algunas de las más importantes revistas medidas por su impacto. Sin lugar a dudas, se requiere un repensar de la investigación contable en Colombia y trabajar en el sentido que plantea Palea (2017) para el caso europeo, donde se promueva una investigación contable arraigada en el contexto económico, político y social colombiano, pero que su calidad teórica y metodológica no esté en discusión y pueda lograr en consecuencia una mayor cobertura, donde vale la pena también considerar el inglés como idioma para publicación no solo a nivel internacional sino a nivel local.

\section{III.III. Michael Andrés Díaz - Activos}

En la última década, las discusiones disciplinares que se han dado en las revistas académicas contables locales, han mostrado un avance gradual acercándose tímidamente a los debates internacionales. Esto se refleja por una participación moderada de un grupo de académicos que han contribuido a los desarrollos teóricos de alto nivel, sin embargo, todavía se sigue presentado una acentuada brecha. La labor de las editoriales es crucial en este cometido (aun con todas las limitantes institucionales que se puedan presentar); la agremiación en redes y la participación en eventos académicos ha permitido incentivar la visibilidad y desarrollo de las revistas nacionales. Además, se ha logrado encontrar un espacio para plantear preocupaciones comunes y fijar objetivos y estrategias mucho más claras que apunten simultáneamente al desarrollo de la disciplina en el país y buscar una voz en las discusiones internacionales (Gómez, 2012; Macías, 2014).

Para respaldar estos esfuerzos, el profesor Macías ha insistido en la integración de las revistas contables colombianas en la academia brasilera resaltando su amplia trayectoria y dedicación en el fortalecimiento de las líneas de investigación y en los medios de divulgación, considerando, además, que es el modelo más maduro de la investigación científica en Latinoamérica. Destaca las características de los autores y las instituciones en el campo científico, los temas abordados en los eventos académicos, el número, temáticas y calidad de las publicaciones seriadas, los atributos de sus revistas, etc. (Macías, 2018), los cuales podremos tomar como un buen referente para proponer algunos objetivos de mediano plazo. Sin embargo, se siguen presentando varias barreras 
Arias, J. D., et al. Aproximaciones contextuales sobre el devenir de las revistas contables colombianas...

a las que se enfrentan las revistas. Una de ellas es la falta de herramientas y la propia disposición de los académicos para acercarse a publicaciones en otros idiomas, lo que está llevando a su vez a una desactualización con los planteamientos que se están adelantando a nivel internacional; se pueden encontrar textos que replican discusiones que se dieron hace ya varios años y el valor agregado puede ser minúsculo o nulo. Actualmente se debe garantizar que las publicaciones contengan referentes internacionales y que la argumentación se equipare con los discursos del primer mundo.

De otra parte, los parámetros fijados por las instituciones como Minciencias y la presión de las propias universidades por hacer encajar a las revistas en rankings internacionales, han llevado a que sigamos divagando en algunas cuestiones, por ejemplo ¿Cuál es el rumbo que deben llevar las revistas contables en Colombia? ¿La tendencia es que desaparezcan por el afán de cumplir con los modelos actuales? ¿Se están direccionando los esfuerzos a cumplir con un listado de requisitos y se está dejando de lado la verdadera investigación? En un sentido muy amplio de la investigación contable en Colombia y en particular sobre la labor de las revistas académicas contables, es poco el camino recorrido y los aportes siguen siendo escasos, no obstante, se sigue fomentando la cultura investigativa y se continúa fortalecido la investigación formativa como motor de estudios más rigurosos para un corto y mediano plazo (Macías, 2017; Patiño, Melgarejo y Valero, 2018; Castaño, 2019). La participación en escenarios internacionales, congresos, redes de investigación, presencia en revistas de alta categoría, coautoría con autores de alto reconocimiento nacional e internacional y el trabajo colaborativo entre los investigadores y editores, permiten un progreso mucho más consistente.

\section{III.IV. Héctor José Sarmiento - Teuken Bidikay}

Efectivamente, el modelo de medición de impacto mediante citas y referencias sirve al propósito de cuantificar la difusión de la producción, pero incuba también el germen de la distorsión de su calidad, como hay ejemplos incluso en las más reconocidas publicaciones del norte industrializado. Este modelo asegura que las revistas de mayor impacto sean aquellas cuyos artículos son más citados en otras revistas de similares características (Macías, Gómez y León, 2012); no obstante, al examinar algunas de ellas en detalle se evidencia -entre otras prácticas de dudosa reputación- un esquema de citación en serie sin mayor pertinencia. Hechos constatados y afirmaciones evidentes, que no requieren ningún apoyo de autoridad, son respaldados por múltiples referencias a textos que no son puntualmente citados y que muchas veces no respaldan específicamente la afirmación. Sin embargo, la captura de las referencias alimenta efectivamente el cálculo de citaciones y eleva artificiosamente algunos índices como el h5 de los autores. En el caso colombiano esta dinámica se ve 
alimentada -entre otras causas- por la presión institucional para imitar las "buenas prácticas editoriales" de las llamadas "revistas de impacto" (GómezZapata, 2019), y por algunos trabajos bibliométricos que elevan al estrellato académico a revistas, autores y textos, sin mayor análisis y por el simple hecho de puntear alto en los índices de citación.

La creciente preocupación por el elevado número de revistas contables en Colombia (Rueda, 2009), tuvo en el caso de Teuken Bidikay, una respuesta desde el mismo momento de su creación como un proyecto de coedición latinoamericano y latinoamericanista, que reúne cinco universidades de tres países y que mantiene abierta la puerta a otras vinculaciones. Esto ha garantizado que esa revista mantenga y fortalezca su perfil, afiance la integración de sus miembros y aleje el fantasma de la fusión con otras publicaciones. No obstante, esto no basta para eliminar la angustia de que salvo por algunas honrosas excepciones- no se estén dando discusiones de avanzada en el campo de la contabilidad en Colombia (Gómez-Villegas, 2013) y, sobre todo, que no se esté construyendo una comunidad científica de la disciplina, más allá de la afinidad profesional y la afectividad personal. La necesaria confrontación de los textos se reduce al "breve espacio en que no estás" de algunos eventos académicos, donde algunos autores eluden la confrontación y otros están de paso, de manera que el tiempo no permite examinar en detalle los argumentos, y los cuestionamientos se limitan a la formalidad de las presentaciones.

Con respecto a la visibilidad de la investigación contable colombiana, existe una gran tensión entre los investigadores porque con excepción de autores como Mauricio Gómez-Villegas, Colombia está ausente de las grandes discusiones internacionales de la contabilidad. Nadie discute que los autores colombianos son muy reconocidos en el ámbito latinoamericano, lo cual podría bastarnos para consolidar una comunidad investigativa en la región, donde incluso podemos liderar procesos de transformación; pero para muchos el verdadero cambio sería entrar en las comunidades anglo, donde hasta ahora la presencia es casi nula. La presión del colonialismo intelectual anglosajón mantiene adecuadamente divididos a los autores contables colombianos e impide la unión de lo que podría ser un verdadero movimiento alternativo en contabilidad, que no intente "ser como ellos" y se decida a ser lo que es.

\section{III.V. Jane Andrew, Christine Cooper, Yves Gendron - Critical Perspectives on Accounting ${ }^{2}$}

Históricamente, sabemos que la mayoría de los escritos académicos más influyentes están publicados en idiomas diferentes al inglés. Por ejemplo, el ganador del Premio Nobel Santiago Ramón y Cajal, que es ampliamente

2 El texto original fue presentado en inglés y traducido al español con autorización de los autores. 
Arias, J. D., et al. Aproximaciones contextuales sobre el devenir de las revistas contables colombianas...

considerado como el padre de la neurociencia moderna, publicó una gran cantidad de artículos científicos en español, francés y alemán. El capital de Karl Marx se publicó originalmente en alemán, al igual que los primeros artículos influyentes de Albert Einstein. El trabajo de Marie Curie se publicó en francés. Los principios matemáticos de Isaac Newton fueron escritos en latín. Sin embargo, en 2020, la mayoría de las investigaciones científicas se publican en un solo idioma: inglés. En algunos países europeos, el número de publicaciones en inglés es sustancialmente mayor que el de publicaciones en el idioma nativo. Algunos informes muestran que en los Países Bajos esta relación es de 40 a 1. Reconocemos que el dominio y la ascendencia del inglés como la lengua franca para la investigación es menos prevalente en los países latinoamericanos, sin embargo, las presiones para publicar en revistas "internacionales" (es decir, en inglés) son palpables y posiblemente esté creciendo en muchas de las universidades latinoamericanas.

Este cambio linguístico necesita enmarcarse dentro del estudio de la economía política del proceso de publicaciones científicas, más si cabe teniendo en cuenta las características de su proceso laboral. En términos del proceso laboral, la gran mayoría del trabajo necesario para producir una publicación en una revista científica, la escritura, presentación en congresos, revisión y trabajo editorial es realizado por académicos empleados en instituciones financiadas con fondos públicos. Para la mayoría de los académicos, el trabajo dedicado a elaborar publicaciones académicas se realiza en su "tiempo libre", los fines de semana, durante las vacaciones y hasta altas horas de la noche. El oligopolio de las compañías editoriales se beneficia enormemente del trabajo de los académicos y no les paga este trabajo excepcionalmente duro. Las compañías editoriales proporcionan la tecnología, la estructura, el diseño, etc.; sin embargo, estos servicios constituyen una pequeña parte del trabajo involucrado en el proceso de elaboración de una publicación académica.

Para muchos de los académicos que desarrollan sus investigaciones en sus horas no-laborales, existe una constante "presión para publicar" en revistas "prestigiosas". Hay solo unos pocos sistemas de clasificación de revistas que dictaminen qué revistas merecen ser calificadas de prestigiosas; la mayoría de los rankings de revistas se basan, principalmente, en el número de citas recientes. Este factor solidifica el dominio del idioma inglés en la academia. Las revistas que publican en inglés dominan estos sistemas de clasificación. Por ejemplo, Scimago muestra que, de las 50 mejor clasificadas revistas en todas las áreas temáticas, 49 provienen de compañías editoriales estadounidenses y británicas, y todos los artículos de esas revistas están en inglés.

Una búsqueda similar de los 50 principales artículos en la categoría de "Business Management and Accounting", demuestra que todos están publicados 
en revistas en inglés, y 46 provienen de editoriales estadounidenses y británicas; los cuatro restantes son revistas de Elsevier (Países Bajos). A su vez, se encuentra un patrón similar para el factor de impacto de Clarivate. En consecuencia, de entre las 103 revistas incluidas en la categoría "Business, Finance" (para el año 2018) del Social Sciences Citation Index (SSCI), encontramos solo dos revistas con un nombre en español (clasificadas en las posiciones 64 y 90 , respectivamente en orden decreciente) y una con un nombre en francés (clasificada en la posición 96). El mensaje es claro: las revistas que publican en inglés supuestamente constituyen el núcleo de la disciplina "Business, Finance", mientras que las lenguas extranjeras están relegadas a la periferia. Por los tanto, ver que el factor de impacto se utiliza para evaluar la investigación en muchas instituciones que no son de habla inglesa es, por lo menos, un enigma, el cual margina diferentes idiomas y estilos y temas de investigación. Además, ver la fascinación que muchos académicos tienen actualmente por el factor de impacto de dos años de Clarivate, constituye una aberración, un total sinsentido dado el tiempo que lleva producir y publicar investigaciones en las ciencias sociales.

En muchos países, estos sistemas de clasificación de revistas dominados por el inglés se utilizan para juzgar la "calidad" de las publicaciones académicas. Si alguien quiere ser visto como un académico de "calidad", está virtualmente "obligado" a publicar su trabajo en inglés, porque las revistas mejor clasificadas en los rankings, por supuesto, son revistas de habla inglesa. Incluso los trabajos publicados en otros idiomas tienen alta calidad, importancia social y/o científica, probablemente no serán muy citados porque es extremadamente improbable que aquellos que publican en las principales revistas, las denominadas "top", tengan el tiempo para, o la voluntad de, leer estos documentos, y en consecuencia no serán citados. Los rankings crean la ilusión de que las revistas de habla no inglesa son de menor calidad.

Otro factor institucional importante es que las principales compañías editoriales tienen una fuerte participación en, o son propietarios de los sistemas de clasificación de revistas. Por ejemplo, Springer posee SJR Scimago y Elsevier posee Scopus. En efecto, las empresas editoriales tienen un modelo de negocio que se basa en la apropiación privada de la mano de obra pública; y están cómodos perpetuando estos "círculos virtuosos", que mantiene la posición de élite (y, en consecuencia, la rentabilidad excesiva) de sus revistas en inglés. Como resultado de todo esto, sería prácticamente imposible para una revista que no está en inglés obtener las citas necesarias para mejorar sus posiciones en las clasificaciones.

¿Esto realmente importa? Creemos que sí, es extremadamente importante por muchos motivos. Nos centraremos ahora en dos. En primer lugar, está la cuestión de la equidad. El área de la edición de trabajos académicos es 
Arias, J. D., et al. Aproximaciones contextuales sobre el devenir de las revistas contables colombianas...

completamente injusta. No se puede subestimar el esfuerzo requerido por los hablantes no-nativos de inglés para publicar en esta lengua. Aparte de la cantidad significativa de tiempo que lleva aprender un segundo idioma, especialmente al nivel requerido por las revistas científicas; la capacidad de publicar en inglés requiere también que los académicos se integren en el trabajo de determinadas revistas. Esto podría llevar más tiempo a los hablantes nonativos de inglés, especialmente en las primeras etapas de sus carreras. A su vez, también significa que hay un número creciente de académicos en todo el mundo que no logran integrarse en el trabajo de las revistas en su propio idioma.

Esto nos lleva al segundo factor que hace que la hegemonía del inglés sea un tema importante. Las palabras, que constituyen la estructura compleja de cualquier idioma, no son simplemente grupos de letras que tienen una asociación directa con un objeto en particular. Las palabras conllevan fuertes asociaciones histórico-culturales. Algunas ideas, entendimientos o formas de entender simplemente no son traducibles; por lo tanto, si todo el pensamiento académico se basa en el inglés, corremos el riesgo de perder formas de comprender, formas de pensar e ideas muy importantes. Perdemos "biodiversidad" de pensamiento.

Los editores de Critical Perspective on Accounting (CPA) somos conscientes de la gran importancia de los temas que estamos tratando en este documento. Reconocemos además que se requieren cambios políticos, sociales y económicos fundamentales para abordar algunos de ellos. Mientras tanto, hemos decidido adoptar un enfoque "pragmático" y al menos tratar de hacer algo. En consecuencia, CPA acepta ahora envíos en inglés, francés y español. Los manuscritos pasan por el proceso editorial en el idioma en que fueron enviados. La traducción al inglés solo se realiza una vez que se acepta un manuscrito. Nuestra política linguística pronto se publicará en un editorial de CPA. Todo esto, esperamos, comenzará a cambiar las formas de las métricas y los factores de impacto de manera que reflejen la diversidad linguística involucrada en la producción del conocimiento. Pero, para hacer cambios más grandes, necesitamos un movimiento social más fuerte de académicos con la voluntad de cambiar las cosas. Esperamos que este documento pueda ayudar a mantener el debate sobre lo que hay que hacer.

III.VI. Laura C. Acosta, Daniel S. Malaver, Víctor M. Castañera - Innovar

Como editores y académicos, reconocemos la importancia de las revistas académicas como órganos fundamentales para la difusión del conocimiento, la construcción de debates y comunidades alrededor de una disciplina. Por ello, la discusión sobre el modelo de medición del IBN-Publindex y las convocatorias de indexación y homologación nos atañe directamente. Sin embargo, creemos 
que Publindex no debe entenderse por fuera del Sistema Nacional de Ciencia, Tecnología e Innovación (SNCTeI). En este contexto, la medición del trabajo académico de sujetos, grupos de investigación, la acreditación de los programas y la calidad de las instituciones, entre otros aspectos, moviliza un emergente cálculo que jerarquiza, clasifica y estratifica (Humphrey y Gendrom, 2013) el trabajo académico en aras de una supuesta eficiencia, eficacia, productividad, calidad y excelencia (Vega-Cantor, 2015).

Publindex, como instrumento de política pública, tiene como objetivos estandarizar los criterios de calidad y visibilidad nacional, así como aumentar la competitividad de las revistas nacionales con respecto al panorama internacional (Charum, 2004; Rodríguez, Naranjo y González, 2015). El modelo de medición, por medio de convocatorias bianuales, con el tiempo se ha modificado según las políticas públicas de Ciencia y Tecnología (CyT) y actualmente se encuentra en un estadio que nos hace cuestionar si realmente sus criterios de evaluación permiten alcanzar los objetivos de calidad, visibilidad y competitividad propuestos inicialmente (Alperin y Rozemblum, 2017). Desde la convocatoria 768 de 2016, se tomó como base para la clasificación dentro del IBN-Publindex el impacto de una revista según el Factor de Impacto (FI). Este viraje generó descontentos, rechazos y resistencias dentro de la comunidad académica colombiana (Gómez-Morales, 2019). El FI es un indicador bibliométrico que "indica la cantidad promedio de veces que una determinada cantidad de artículos de una revista ha sido citada en otros artículos durante un año (ventana de citación)” (Beltrán-Medina, 2017, p. 133).

Esta métrica, así como su inclusión en la política pública de CyT, ha promovido una diversidad de críticas, algunas de carácter técnico-estadístico y otras de carácter socio-político. En el primer grupo destacamos: la ausencia de criterios de relación entre la calidad del trabajo individual y la revista (Molas-Gallart y Rafols, 2018; Adams, McVeigh, Pendlebury y Szomszor, 2019); la irrelevancia de la asociación de propiedades e indicadores en determinados contextos, disciplinas y lenguas (Molas-Gallart y Rafols, 2018); y, la arbitrariedad en la ventana de citación y en la normalización estadística para la comparación de las citaciones promedio en un campo (Van Leeuwen, 2012). De estos reparos técnicos devienen las críticas socio-políticas como: el carácter inapropiado para la evaluación de la calidad en las políticas públicas (Molas-Gallart y Rafols, 2018; Adams et al., 2019; Callaway, 2016), la imposición de agendas de lo relevante a investigar en determinados contextos (Molas-Gallart y Rafols, 2018), la presión por la citación de lo novedoso y la competencia estadística en las colecciones donde coexisten contextos epistémicos diversos (Van Leewuen, 
Arias, J. D., et al. Aproximaciones contextuales sobre el devenir de las revistas contables colombianas...

2012), los isomorfismos estructurales y la integración subordinada (GómezMorales, 2015), entre otros. ${ }^{3}$

En la comunidad contable anglosajona, los profesores Humphrey y Gendrom (2013) han señalado que "hemos objetivado las clasificaciones dentro de nuestra comunidad, así como nuestra relativa incapacidad para limitarlas y resistirlas" (p. 50). En la comunidad contable colombiana se ha convocado a la duda sistémica sobre estas mediciones y clasificaciones (Gómez-Villegas, 2013; Rojas-Rojas, 2017; Malaver-Rivera, 2018). Entonces, la capacidad de penetración, el nivel de subjetivación y gubernamentalidad de estas métricas sobre un campo, sus actores y dinámicas, dependerá de la capacidad de internalización o limitación y resistencia. ¿Hasta dónde tales métricas determinan el sentido del trabajo editorial de las revistas contables en Colombia?

Desde Innovar insistimos en algunas de estas críticas e instamos a su debate en la comunidad académica. Las políticas públicas de medición del trabajo académico han profundizado un ethos que desancla el proyecto social e institucional de la Universidad (Vega-Cantor, 2015, De Sousa-Santos, 1998), es decir, la relevancia contextual de la investigación se supedita a los top trendings topics de los investigadores y revistas del norte global-epistémico. Mientras la normalización estadística del factor de impacto suponga que Innovar debe competir con Journal of Finance, Journal of Financial Economics o The Accounting Review, por nombrar algunas, entonces, ¿Innovar es una revista indexada en Scopus pero irrelevante o de baja calidad? Empero, en el contexto latinoamericano, al margen de las casas editoriales y sus métricas citacionales, Innovar se caracteriza por ser un referente de visibilidad y calidad en los campos de la gestión y la contabilidad. Así, invitamos a los proyectos editoriales a reflexionar sobre las implicaciones de estas métricas sobre su identidad, sus prácticas editoriales y sus comunidades académicas. También, somos conscientes de las falencias propias del $F I$ y, en general, de la actual política de clasificación dentro del IBN-Publindex. No obstante, es de esperar que al menos en el mediano plazo el $\mathrm{FI}$ siga siendo un referente, de suerte que instamos a que los órganos competentes, caso de Minciencias, consideren en las venideras convocatorias de clasificación, que los criterios de calidad de los procesos editoriales tengan un peso mayor a la hora de otorgar una clasificación y poner en contexto al FI. Para hacer más "justa" la comparación, se recomienda prestar atención al ámbito geográfico de las revistas como criterio de agrupación, no solo a las áreas de conocimiento, de suerte que se evite invisibilizar temas de investigación que son de interés para una comunidad en particular (ej.

3 Con base en la diversidad de críticas al FI, el Manifiesto de Leiden y la Declaración de San Francisco sobre la Evaluación de la Investigación - DORA han surgido como referentes de oposición y propuestas alternativas de valoración de la calidad del trabajo académico. 
académicos contables en Colombia), mas no para el mundo académico del norte global-epistémico, lo cual se suscribe a lo indicado por Callaway (2016).

\section{III.VII. Yuliana Gómez Zapata - En-Contexto}

Hace poco planteé la necesidad de reflexionar sobre el proceso de medición realizado por Minciencias para las revistas científicas en Colombia, trabajando preguntas sustanciales sobre el cómo y el para qué de esas mediciones. Esas reflexiones estaban marcadas por la sensibilidad que me genera participar de escenarios académicos y escuchar a algunos colegas cuestionar públicamente la forma de medición de las revistas científicas en Colombia, pero también aquellos que la avalan; y digo que me genera sensibilidad porque es el martirio con el que los y las editores de revistas nos enfrentamos en el día a día. "El (...) impacto en la generación de ciencia en Colombia, advierte una conducta sociológicamente patógena en cuanto a los intereses de colectivos científicos que proponen un pensar desde nuestro contexto y bajo la resolución de problemáticas propias" (Gómez, 2017, p. 42), al privilegiar la lógica bibliométrica por encima de la utilidad pública del conocimiento (Gómez-Zapata, 2019, p. 35). Estamos confundiendo el sentido de nuestras publicaciones, estamos privilegiando el indicador por encima de la utilidad de conocer y de la circulación de eso que se conoce. La ciencia y su conocimiento experto debe servir para resolver problemáticas concretas de la sociedad y de las comunidades humanas con quienes trabajamos; ello no puede subvalorarse respecto al número de veces que es citado un manuscrito en lugares que ni siquiera conocemos o no tenemos accesos. Estamos atrapados por las dinámicas de la productividad académica, no necesariamente de calidad.

Ya lo planteaba el profesor Gómez-Morales (2018), pues existe en el país una incomprensión sobre los procesos de medición e indicadores de calidad que define el modelo propuesto por Minciencias para la clasificación de revistas científicas en Colombia, pues el Estado “(...) formula políticas de ciencia cuyas consecuencias sociales y culturales se pasan por alto al confundir el indicador con las metas de política" (p. 273). Entonces sí que vale la pena preguntarnos, ¿cuál es el sentido de nuestras publicaciones? ¿Qué es lo que queremos resolver con ellas? ¿Para qué las exponemos en una comunidad científicoacadémica? ¿Para qué nos esforzamos haciendo investigación? La respuesta, en mi opinión, es mezquina; para hacernos visibles, para obtener más recursos económicos, para no perder nuestro empleo, para ampliar nuestra vanidoteca, para competir con otros y otras, entre otras razones igualmente inútiles. Ahora bien, no encuentro, en la mayoría de los casos, intencionalidades que desvelen la necesidad de aportar a la resolución de problemas. Espero ser fatalista y equivocarme en esta precisión. Sobre el particular de si las métricas inducen a la eliminación o unificación de las revistas colombianas contables, quiero 
Arias, J. D., et al. Aproximaciones contextuales sobre el devenir de las revistas contables colombianas...

decir que creo que lo hacen, pues generan una suerte de pensamiento único que desgasta nuestra posibilidad de disenso y nuestras prácticas de resistencia epistémica.

Nuestras revistas colombianas no logran participar en discusiones disciplinares internacionales situadas en índices como WoS o Scopus, pues coexisten en nuestros contextos académico-científicos revistas que, si bien cuentan con buenos procesos y modelos de gestión de calidad, que desarrollan dignos planes de mejoramiento para que su publicación sea más visible y confiable, no logran entrar en esas dinámicas internacionales tan codiciadas y veneradas por muchos y muchas, pues no se logra tener el capital cultural y simbólico que se requiere para que esas comunidades te asignen un espacio (Gómez-Zapata, 2019, p. 36). Tenemos el compromiso de ser capaces de reconocer nuestro aporte a la construcción de conocimiento a través del texto escrito, con dificultades y aciertos, pero con dignidad académica. Es una invitación académico-política para que nos pensemos en contexto y desde nuestras propias posibilidades de crear y soñar.

\section{III.VIII. Juan David Arias - Revista Colombiana de Contabilidad}

Ya se ha indicado que la cienciometría representada por rankings a través de Scimago y el factor de impacto a través de citas son criterios discutibles, pero la evidencia empírica de años de ejecución de esta forma de medición de la ciencia hace arguiir que son criterios antidemocráticos, asimétricos y que se erigen como nuevas formas de colonización y dominación sobre el saber otro. En esa vía, algunos editores recientemente reconocen estas asimetrías en la medición y su resistencia para engendrar esta especie de 'juegos superficiales', perversos, productores de ansiedad y generadores de efectos marginales (Andrew, Cooper y Gendron, 2020). De hecho, artículos recientes demuestran que el impacto de las publicaciones medido a través de citas es una medida abusiva, sin sustento empírico (Gómez-Morales, 2018) que termina siendo un mito (Erzsébet, 2018). No obstante, las preocupaciones ya no solo son 'publicar o perecer', sino que se han trasladado al 'impactar (con citas) o perecer', tal como lo demuestran Biagioli y Lippman (2020), donde muchos académicos, buscando alcanzar metas, han construido una estratagema de malas conductas y manipulaciones en la investigación para insertarse en el juego de las métricas.

Entre otros temas relevantes de la discusión, hay algún argumento como el de Macías (2020) que afirma que "la tradición nacionalista de la investigación contable colombiana ha mantenido marginada la investigación" en contabilidad frente a la dinámica internacional, actuando con una "negación deliberada a intercambios con la academia angloparlante". Sobre ello es importante dilucidar que, si bien las posiciones políticas y defensas ideológicas son válidas en los avances científicos, hay matices y perspectivas diversas en la tradición 
contable nacionalista, sobre la cual es indiscutible su compromiso y aportes al desarrollo de la investigación contable en Colombia y Latinoamérica. Sin embargo, la constante resistencia a la interacción con colegas foráneos versa en la defensa al sometimiento de una academia externa que se autodetermina como hegemónica de la razón en contabilidad, la confianza en los aportes nacionales propios y el contundente rechazo a ser parte del marketing prolucro de la institucionalidad de muchas de las casas editoriales comerciales internacionales.

Al respecto cabe anotar que 'insertarse' en las discusiones internacionales más allá de Latinoamérica, no puede ser visto como insertarse, solo y exclusivamente, en las publicaciones anglosajonas; los medios de comunicación de la ciencia, como lo son las revistas, son solo medios y partes del proceso de construcción académica. Sea esta la oportunidad para hacer una crítica a los profesionales e instituciones que destinan más tiempo a buscar aliados internacionales para publicar 'conjuntamente' como estrategia de subir en los rankings, que a las investigaciones propiamente, convirtiéndose, en la mayoría de los casos, en alianzas estériles para la investigación y el avance del conocimiento. Como lo indica Johnny Orejuela, Jefe del Departamento de Psicología de la Universidad Eafit, se debe 'investigar sin angustia', ya que pareciera que hoy día el miedo es generado por un artículo rechazado, por 'no publicar', y no por no contribuir a la comunidad.

El origen e interés del MEN sobre la forma de medir la calidad de las publicaciones han sido desenmascarados constantemente en público, donde se ha hecho notoria la incapacidad institucional de crear (o cuando menos, adaptar) modelos de medición alternativos, amplios y al margen de la carrera del citatón ${ }^{4}$ y el ranking show, lo cual permite indicar que la inserción en discusiones académicas de revistas internacionales (anglosajones, partícipes de los rankings) no se basa en capacitarse en la forma (estructuras de los artículos, citas correctas, metodologías tradicionales o trending topics) sino en avanzar en el fondo, en la verdadera y relevante discusión sobre el avance disciplinar encaminado a solucionar problemas de la realidad concreta, pues el fin social del conocimiento, el fin de publicar (hacer público, divulgar) no es más que coconstruir un herramental científico formal para el buen vivir. Empero, esta suerte de novela de ciencia ficción de publicar como fin, ha terminado alimentando el ego y mal-legitimando las ideologías subyacentes de los mercaderes de Scopus y su cinismo ortodoxo. Por supuesto hay quienes hacen un trabajo juicioso, ampliando fronteras académicas a partir de la interacción con académicos de

4 No se debe olvidar que la medición de calidad a través del cálculo del factor de impacto tuvo un origen funcional como criterio de identificación de las revistas a comprar por bibliotecarios, y no como una medida real de calidad científica. 
Arias, J. D., et al. Aproximaciones contextuales sobre el devenir de las revistas contables colombianas...

otras latitudes, cuyos resultados para el avance de la disciplina y la profesión son notorios.

\section{III.IX. Luisa Fernanda Giraldo - Lúmina}

En una disertación anterior sobre el estado actual y el futuro de las revistas contables colombianas, se reconocen dos posturas, aquella que rescata la adopción de modelos internacionales para legitimar y medir la calidad y avance de la investigación, y otras que reclaman una dinámica de investigación que responda al contexto regional y local (Macías, 2014). Hoy esa tensión es aún mayor, el presente siglo trajo consigo una responsabilidad adicional para los profesores universitarios, investigar y publicar en revistas académicas o científicas mal llamadas de "primer nivel", con el fin de no quedar ausentes de reconocimiento, de puntos y estímulos económicos ante un modelo de medición cuantitativo que valora la cantidad y no propiamente la calidad del desempeño institucional y de los investigadores, lo que Sarmiento (2018) llama una nueva forma de colonialismo, permitir que la lógica de la incertidumbre del mercado determine la construcción del conocimiento.

Maldonado y Pérez (2018), ponen en cuestión los altos riesgos éticos que acarrea la dinámica antilógica de las publicaciones, las cuales se preocupan por métricas más que por el impacto social de la investigación (Arias, 2018). En lo que algunos autores conocen como la sociedad de la información inmersa en un "capitalismo académico" (Maldonado y Pérez, 2018), la contabilidad atraviesa un estancamiento disciplinar y profesional porque los académicos y los investigadores están preocupados por rendir en lógica eficientista y competir entre ellos por mejores categorías; se perdió el legado, la tradición y el faro que guio el rumbo de los desarrollos contables entre los años 70 y 90 , que gracias a la fuerza de la agremiación profesional y motivados por unos intereses colectivos, fue posible plantear una postura y una defensa por la dignificación y el rol social, político y ético que cumple el contador en la sociedad. El reto que aún no se ha resuelto y ha sido difuminado por las presiones del modelo de medición, está en la construcción de redes de conocimiento, articulación de la academia contable, consolidación de las comunidades científicas y en pensar conjuntamente la contaduría y la contabilidad; es urgente, romper la barrera del "tú me citas, yo te cito", para comprender que "lo relevante no puede ser el papel que jugamos en el entorno mundial, sin aún conseguir la cohesión, presencia y respuesta a las necesidades del contexto" (Gómez, 2013, p. 282).

En este marco de escribir por cumplir indicadores, es urgente la invitación que presenta Malaver, volver a las preguntas esenciales, ¿para qué? (2018), o cómo lo menciona Sánchez ¿para quién se producen los contenidos editoriales? (2019), "buscar que las revistas lleguen a ser incluidas en ISI, SCOPUS, SciELO o cualquier otro sistema no puede convertirse en su propósito 
final, sino en un resultado asociado a la consolidación de comunidades académicas e investigativas" (Rueda, 2012, p. 13). Cualificar la investigación, interactuar y actuar en torno a las problemáticas propias de la disciplina y la práctica, preguntarse por la pertinencia de los métodos utilizados para leer el contexto y responder a las necesidades, de lo contrario todos los esfuerzos estarán aislados y solo atenderán los egos intelectuales para buscar un mejor posicionamiento individual o institucional, dejando a un lado el potencial del trabajo en red para conformar comunidades académicas y científicas que verdaderamente movilicen los debates y las barreras del conocimiento.

Es momento de reconocer y retomar los esfuerzos de las generaciones de vieja guardia y ponerlas a dialogar con las posturas emergentes de los pensadores contables colombianos, para mediar entre los intereses institucionales y los esfuerzos editoriales, para resistir a los criterios de eficiencia académica y actuar de forma propositiva siendo coherentes con la naturaleza científica y académica y hacer una ruptura urgente para "oponernos a creer ciegamente que somos mejores si nos visibilizamos en los JCR" (Rojas, 2017, p. 96) y que por esta senda, la investigación y su divulgación permitan reconfigurar la herida colonial.

\section{III.X. Julieth Sorany Alzate - Visión Contable}

El actual mundo de las publicaciones se distingue por la turbulencia métrica. Pareciera ser que en el ambiente de las revistas importasen más los esnobismos tecnológicos y la cuantificación de la citación que las discusiones académico-científicas. De dichas discusiones depende el avance pertinente del conocimiento, con el fin de que siga una senda coherente y construccionista. Las publicaciones no deben auspiciar la atomización del saber disperso e individualista, donde se carece de la conversación y la construcción colectiva de paradigmas teóricos. Las presiones institucionales, especialmente de universidades y de casas editoriales, han ido en detrimento de estas discusiones teóricas. Las exigencias desaforadas de las instituciones, que van desde tiempos reducidos para la ejecución de los proyectos de investigación, hasta el requerimiento de un número incoherente de productos, han puesto en jaque a los investigadores, al punto de que éstos se ven en la obligación de pagar a las revistas por la publicación de sus trabajos. Por suerte, la mayor parte de las revistas no sujetan la publicación de los artículos a los recursos de los autores. Para el caso de Colombia, las revistas son proyectos de las universidades o asociaciones gremiales que deciden apostar algún recurso a la reproducción de conocimiento actualizado de la región.

En sintonía, Colombia es un caso particular en el estadio editorial contable. La intención genuina de las revistas contables ha sido la reproducción de las reflexiones disciplinares, que hasta hace poco carecían de una metodología 
Arias, J. D., et al. Aproximaciones contextuales sobre el devenir de las revistas contables colombianas...

declarada. Las publicaciones contables han tendido al abordaje de temas sociales-cualitativos, con una menor participación de trabajos cuantitativos. Muestra de ello es el perfil de las revistas contables, gran parte de estas publican trabajos reflexivos-a priori y de temas mixtos, son revistas flexibles temática y metodológicamente. Pero la publiometría internacional propone que las revistas tomen una línea temática específica dentro de las mismas disciplinas. A esto se le suma, que la tendencia internacional es de perfil cuantitativo, hegemónico por el discurso de exactitud y verdad legitimado en la academia. Este panorama ha dejado por fuera a muchos de los investigadores contables que quisieron participar del fuero extranjero y adicionalmente ha puesto en desventaja a las revistas nacionales frente a las publicaciones internacionales.

Si a lo anterior se le suma la hegemonía del idioma inglés, tanto las publicaciones como los investigadores colombianos se sitúan al margen. Cabe aclarar que la dinámica de la academia contable colombiana, en la última década, ha permitido que los trabajos transiten de ser reflexivos a declarar una metodología y una corriente teórica. Esto ha sido promovido por el surgimiento de programas de maestría en donde se han instruido los nuevos investigadores y a la formación de algunos profesores en doctorados extranjeros; se trata entonces de una herencia a destacar de la academia internacional. Sin embargo, no se debe dejar de lado la tradición de la academia contable nacional. Estar a la saga de los desarrollos internacionales no permite el reconocimiento de la valía de nuestra tradición, de lo autóctono, que responde a las dinámicas de este contexto. En muchas esferas del conocimiento, pareciese que la panacea fuese lo foráneo y se olvida la riqueza de nuestra idiosincrasia. Lo externo y lo interno no necesariamente tienen que apuntar al mismo horizonte, cada país debería abogar por las métricas que posibiliten el fortalecimiento de su tradición académica. Las instituciones nacionales deben comprender esto, pero apuntan a medirlo.

La construcción de comunidades académicas nacionales y latinoamericanas nos debe conminar a repensar la pertinencia de la cienciometría internacional, tomando posición y evaluando de manera crítica sus modelos. La potenciación de las virtudes de cada pequeña academia, representada en sus publicaciones, debe fortalecerse de manera interna y posteriormente establecer conversaciones y puntos de encuentro con los trabajos exógenos. Debemos confiar en las capacidades de nuestra región para la generación de nuevo conocimiento y en el enfoque de las revistas que lo divulgan. 


\section{III.XI. Marisleidy Alba - Apuntes Contables}

En el contexto contemporáneo de medición de la investigación ocupan un papel protagónico los artículos publicados en revistas indexadas, prueba de ello es que los estándares de medición actual están introduciendo una tendencia que es escribir para citar y citar para escribir, lo cual se ha vuelto un círculo vicioso en el que es posible socializar el conocimiento y las buenas prácticas pero se desvirtúa la esencia de la investigación como proceso, alejando a los investigadores del propósito científico de identificar problemas para buscar una solución. Estas prácticas en las cuales los investigadores e instituciones se ven inmersas constituyen la vía para lograr los indicadores de medición exigidos.

En este escenario de altas métricas, la contabilidad y las revistas que se encargan de difundir el conocimiento sobre ciencias sociales en Colombia, quedan en un nivel inferior de aquellas que relacionan investigaciones sobre tecnología e innovación. No se puede desconocer la importancia de la investigación para la competitividad, ni la importancia de investigaciones basadas en métodos cuantitativos. Pero eso no prohíbe que se requieran investigaciones sobre humanismo, estudios sociales, convivencia social, política y económica. Ante esta situación, las revistas encargadas de promover estos temas y que además consideran en sus números artículos que aportan a los departamentos, municipios, zonas, etc., están obligadas a perecer o a cambiar de filosofía. Las métricas actuales de posicionamiento obligan a las revistas de mejor ubicación a no considerar estudios de caso y en poca medida investigaciones que no demuestren métodos cuantitativos.

En este panorama tan complejo de publicación, se está olvidando la esencia de la investigación como proceso y desde su impacto. Está bien que existan diferentes métricas, pero no es serio que el impacto solo se pueda ver en artículos publicados en revistas top (Q1...Q4) donde no es posible incluir otras investigaciones que también impactan en su localidad solo porque no cuentan con métodos cuantitativos o se concentran en su caso de estudio, ante esta situación surgen las siguientes interrogantes: ¿es que existe un único método de investigación? ¿Por qué entonces autores reconocidos como Roberto Hernández Sampieri o Ryan, Scapens y Theobald hablan de diferentes enfoques? ¿Por qué no incluir otras métricas alternativas de evaluación de impacto que permitan incorporar otro tipo de estudios y con ello otras revistas? Las instituciones deben ser conscientes de que se debe hacer investigación pertinente y de impacto, reconociendo la pertinencia como la oportunidad para trabajar temas necesarios en un momento dado y que impacten en la sociedad, en el desarrollo de nuevos conocimientos, en la tecnología, así como en otras investigaciones. 
Arias, J. D., et al. Aproximaciones contextuales sobre el devenir de las revistas contables colombianas...

\section{III.XII. José Joaquín Ortiz - Criterio Libre}

Se ha vuelto muy importante comprender las dinámicas que se generan alrededor de la investigación en las IES colombianas (Gómez, 2013) para dilucidar su efectividad en los procesos de transformación social y el papel que juegan las publicaciones científicas en ello (Bruni y Magaudda, 2017). Esta reflexión pretende aportar algunos elementos de análisis desde lo que podrían ser las reglas de juego para el diseño de la política científica de nuestros países. Debemos empezar por cuestionar la pertinencia social de la investigación en las universidades colombianas (Ortiz, 2019) que se ha apartado de las verdaderas necesidades del desarrollo humano y socioeconómico del país y se ha circunscrito a plantearse cuestiones de alcance abstracto sobre temáticas que no se salen de desarrollos ideológicos o algunas veces especulativos, o sobre temáticas que se enmarcan en la ciencia tradicional, generando disertaciones que no contribuyen al descubrimiento de nuevos conocimientos aplicables al entorno local, sino a reforzar hipótesis que se han comprobado cientos de veces, pero eso sí, apuntalando alguna diferenciación de matices que en esencia atienden más a la forma, tratando de que los pares lectores encuentren algo importante que permita generar el mayor número de citaciones. En ello se pueden incluir algunos esfuerzos de aplicar modelos matemáticos y estadísticos desarrollados y comprobados en otros entornos, pero que no sufren un nivel de crítica e interpretación nueva para generar conocimientos adecuados a nuestro medio. Sin embargo, no se haría justicia sino se reconocen ciertos enfoques epistemológicos que se pueden calificar dentro de la corriente crítica de las ciencias sociales, pero son precisamente los que no se acogen de manera expedita en las grandes empresas editorialistas, y responden más a la dinámica de los países hegemónicos como beneficiarios de las relaciones económicas asimétricas y que encuentran respaldo en lo ideológico, apoyándose en lo científico, desde las corrientes positivas y cuantitativas, donde no se interesan por la irrupción o la disrupción de nuevos esquemas explicativos, que cuestionen la hegemonía de los poderes económicos y políticos establecidos.

Sobre esta temática ha contribuido el enfoque de medición del impacto de las revistas desde el paradigma del número de citaciones, indistintamente de donde vengan ni qué corriente del pensamiento están reforzando o alimentando o de qué manera aportan a la consolidación de las áreas de conocimiento en cuestión (León, 2009; Rueda, 2012; Macías, Gómez y León, 2012). Es decir, no hay cualificación de esa cuantificación, desconociendo el desarrollo histórico desde lo sociológico y epistemológico de las ciencias sociales. Ello exige repensar nuevos esquemas de valoración cualitativa de esos aportes al desarrollo de la ciencia. Una posibilidad es enfocar las investigaciones (los proyectos desde los cuales emanan los artículos científicos) 
en su planeación y aprobación por las instituciones para que tengan pertinencia en seis perspectivas claves: La social, la económica, la cultural, la política, la académica y la científica.

El enfoque de la pertinencia desde lo social (Garrocho y Segura, 2012) debe contemplar un marco que le dé la pertinencia, bien sea desde el PEI, o desde los Objetivos de Desarrollo Sostenible, o desde los objetivos sociales del plan de desarrollo nacional, etc., y establecer selectivamente a cuál de esos objetivos pretende aportar el proyecto. Desde la perspectiva económica, es importante establecer hacia dónde se dirige el proyecto: a resolver aspectos tanto teóricos como prácticos que contribuyan a mejorar el bienestar de la población, que deben ser claramente identificados. Desde lo cultural, definir qué aspectos culturales busca cubrir el proyecto: Cultura ciudadana, enfoque étnico, desarrollo artístico, análisis de costumbres como patrimonio cultural, desarrollos históricos, etc. Desde lo político, debe establecer los componentes que pretende abordar el proyecto: Participación ciudadana, profundización democrática, concienciación política, expresión de los grupos sociales en la política, etc. Desde la perspectiva académica, se deben explicitar los tópicos académicos en los que puede tener injerencia el proyecto: Rediseño curricular, actualización de currículos de planes académicos, participación de docentes y estudiantes a través de la investigación formativa desde el aula. Finalmente, desde lo científico, establecer el tipo de nuevo conocimiento (en términos conceptuales o teóricos) que pretende el proyecto, establecer los aportes metodológicos novedosos incluidos en el proyecto, como el uso de metodologías cualitativas (estudios etnográficos, relatos de historias, etc.) o diseños de modelos cuantitativos y sus aplicativos en la disciplina y en la ciencia, etc., definir los aspectos en los que el proyecto apunta a fortalecer la fundamentación científica, disciplinar, metodológica, epistemológica, filosófica, etc. de la línea de investigación en que se inscribe el mismo, definir las estrategias de difusión y divulgación de los aspectos anteriores a la comunidad científica y los alcances pretendidos.

Es de aclarar que no todas las perspectivas deben ser abocadas, por lo que se debe precisar el alcance. Si lo planteado es aplicable a la raíz desde donde emanan los artículos científicos, éstos deben conservar esos lineamientos y se deben hacer explícitos en los procesos de difusión a través de las revistas científicas. Así mismo la evaluación tanto por los pares evaluadores, como por las organizaciones que se dediquen a evaluar la calidad de las revistas, deberían incluir este tipo de evaluación cualitativa, por lo que es aconsejable, que esas organizaciones se configuren desde la comunidad académica, que así podría participar más activamente en la conformación de un modelo más integral y que permita el diálogo entre todas las Instituciones interesadas. 
Arias, J. D., et al. Aproximaciones contextuales sobre el devenir de las revistas contables colombianas...

\section{III.XIII. David Andrés Camargo - Revista Facultad de Ciencias Económicas}

Las grandes casas editoriales como oligopolio cartelizado han sido estables al ofrecer productos no competitivos (Guédon, 2011), journals de acceso abierto, de acceso cerrado e híbridos dentro de sus catálogos. Por el carácter comercial de estas editoriales, los contenidos de acceso cerrado les son más lucrativos, porque los contenidos de acceso abierto, no les generan un valor agregado a las bases de datos que venden, ya que el lector los descarga de la web sin restricciones. Hay que tener en cuenta que alguien paga este modelo de publicación de libre acceso, por ejemplo, las instituciones educativas, los gobiernos, las asociaciones de profesionales, entre otros más, que subvencionan la producción y difusión de contenidos seriados y arbitrados (Camargo, 2019). En este modelo de publicación se encuentran las revistas contables en Colombia, donde sin Article Processing Charges (APC), los autores no asumen ningún costo del procesamiento de su producción intelectual, contrario a lo que establecen algunos journals que pueden cobrar entre quinientos y cinco mil dólares por manuscrito aprobado para publicación libre (Camargo, 2018b).

En la búsqueda de aligerar estas cargas para los autores, planes como por ejemplo, el $\mathrm{S}$ en Europa han promovido que para el año 2021 los resultados de investigación financiados con recursos públicos se publiquen en acceso abierto (Science Europe, 2018), y que se establezcan topes a los APC (Johnson, 2019). Iniciativas loables pero poco efectivas, en tanto que los APC se han venido incrementando al igual que los manuscritos postulados y publicados bajo dicho modelo (Khoo, 2019). De ahí que las publicaciones que pagan APC se consideren como un bien de veblen (Camargo, 2019), situación entendible si se observa el creciente afán por divulgar lo investigado, obtener citas y figurar en el mundo académico con publicaciones indexadas en journals de "prestigio" (Khoo, 2019), que en la mayoría de casos cobran cargos. Esta situación deja ver la inelasticidad de la demanda por publicar, frente a los cambios en los APC (Camargo, 2019). Bajo esta lógica mercantil, o se paga por publicar en libre acceso o los contenidos son accesibles únicamente por suscripción a las bases que ofrecen las editoriales comerciales. Es un fenómeno con el que los autores deben lidiar, porque las revistas que cobran cargos no han perdido interés y los APC no han bajado de precio, pese a que muchos journals han hecho el tránsito hacia ese modelo de autofinanciación aumentando la competencia.

De todo esto, se desprenden dos conclusiones: la primera, es que para los autores y financiadores, sumarle un costo más a las investigaciones parece irrelevante, si el capital simbólico acumulado aumenta por publicar en revista de renombre, así cobren APC, por lo que los journals de este tipo seguirán existiendo alejándose de planes como el $\mathrm{S}$ y similares que propendan por el 
acceso abierto y la regulación de los cargos. La segunda conclusión, tiene que ver con la financiación y sostenibilidad de las revistas nacionales (dentro de las que están las del campo contable), que tendrán que pensar en fuentes de financiamiento creativas, sin descartar dentro de las opciones el cobro de APC, por la estrechez manifiesta de recursos por parte de las universidades públicas y privadas (sus principales financiadoras), y para cumplir con las exigencias del modelo nacional de indexación establecido por Minciencias.

\section{Discusión categorial}

Los argumentos presentados sobre las tensiones actuales y contextuales de las publicaciones científicas sobre contabilidad en Colombia, desde las letras y voces directas de quienes conviven cotidianamente con la labor editorial, no solo es importante sino relevante para la comunidad de autores e investigadores de la disciplina contable. La cienciometría y la competitividad universitaria enfocadas en las publicaciones han generado virajes sobre el sentido de la investigación, su ethos y su devenir, para construir un homo academicus y unos journals colmados de 'prestigio' a partir de citas, y en buena parte desentendidos de su realidad social concreta. Las asimetrías entre el origen de los autores, las temáticas desarrolladas, la revista e idioma en que se publica, la comunidad que los lee y su potencial impacto en la vida social y organizacional, son aspectos ciertamente difusos. Posiciones epistémicas, éticas, estéticas y políticas son cuestionadas sobre el ser y el deber ser de las revistas científicas, cuya pugna por ser socialmente acreditadas para ser como en su origen sociohistórico, un lugar de divulgación, de conversación- el ágora de interacción científica aún es una labor pendiente.

Es así como las tensiones y las preocupaciones de los editores sobre las categorías problematizadoras de este documento (modelo de evaluación de impacto; interacción de una comunidad académica; política pública de Ciencia, Tecnología e Innovación; sentido de la investigación) son palpables y permiten comprender que no hay posiciones unívocas, sino que coexisten diferentes perspectivas sobre la forma y el fondo de hacer investigación, su sentido social y las métricas que deberían direccionar la evaluación de calidad e impacto de las revistas.

IV.I Discusión sobre el modelo de evaluación de impacto y la interacción de una comunidad académica (nacional e internacional)

La evaluación e indexación nacional e internacional de las revistas a partir del cálculo del factor de impacto a través de citas es el tema más controversial y discutido por parte de los editores, cuyas posiciones, defensas y discrepancias son evidentes. Sin desconocer las potenciales conexiones e interrelaciones que generan las publicaciones internacionales y las referenciaciones bibliográficas 
Arias, J. D., et al. Aproximaciones contextuales sobre el devenir de las revistas contables colombianas...

desde una lógica relacional interuniversitaria, la crítica constante sobre las métricas, su asimetría contextual e idiomática y sus prácticas colonialmente miopes sobre la forma de hacer ciencia (hegemonía del paper como pensamiento único de la ciencia) tienen un mejor ejercicio de sustentación, y son evidenciadas de las prácticas indelicadas y provechosas de lo que significa el proceso de citación. Es así como puede notarse posiciones diametralmente opuestas entre los argumentos de Salazar, Correa y Díaz, quienes encuentran aspectos positivos sobre la medición de la ciencia de esta forma, frente a las posiciones de Sarmiento, Arias, Gómez, Acosta et al., y Giraldo, quienes la encuentran impertinente y abocan por ampliar la mirada e incluir métricas alternativas que respondan a las particularidades científicas locales e impactos sociales más concretos. El marketing de la ciencia no siempre es el más apropiado si carece de fundamentos académicos, reconocimiento de las comunidades y desvirtúa las lecturas particulares de estudiantes y estudiosos de la contabilidad.

La idea de 'comunidad académica' a partir de las publicaciones es constantemente criticada y plantea imaginarios ambiguos; a pesar de que con mayor frecuencia y calidad autores colombianos publican en revistas internacionales, en la mayoría de las ocasiones esta 'inserción' responde a las lógicas métricas por conseguir una publicación internacional indexada, más que interactuar con una comunidad, pues no es un mito que los académicos aprenden rápido acerca de qué, cómo y a quién citar para aparentar aproximarse a una comunidad, aunado a que es importante reconocer la falta de lectura entre colegas locales, su difusa interacción y la ausencia de confrontación académica en las publicaciones. No obstante, no debe olvidarse que el relacionamiento con comunidades académicas externas a la colombiana no es un asunto exclusivo del diálogo entre las publicaciones internacionales ni nació con las revistas científicas, sino que particularmente en Colombia han coexistido comunidades académicas desde los años 80 que discuten, interactúan y construyen legado científico en contabilidad al margen de las revistas y las citas.

Las tensiones sobre el inglés, como monopolio del lenguaje científico, han sido bien presentadas por Andrew et al., donde se reflejan realidades, desconexiones y sinsentidos de sesgar la riqueza linguiística hacia el reflejo de quienes crearon y controlan los modelos de medición. Diversas posiciones podrían suscitar estas perspectivas, pero también debe reconocerse que las revistas de ciencias sociales colombianas que han optado por publicar únicamente en inglés no han demostrado interacción ni han despertado el interés de las comunidades internacionales, generando una marginación por doble vía. 
IV.II. Discusión sobre el modelo de evaluación de impacto y la política pública de ciencia, tecnología e innovación

Comprendiendo las formas actuales de medición científica, los editores reconocen la imposición de modelos foráneos por parte de las políticas públicas de ciencia, tecnología e innovación, que sin hacer mayor esfuerzo adaptan las tendencias internacionales sobre métricas científicas al contexto colombiano, desconociendo los enfoques y las diferencias entre la producción académica de las ciencias sociales frente a las ciencias naturales, y las desigualdades sobre la asignación de recursos económicos al desarrollo investigativo, científico y tecnológico en el país.

En ese sentido, los editores participantes tienen mayores puntos de coincidencia, resaltando las críticas de Alzate, Gómez, Arias y Acosta et al., y la perspectiva propositiva de Ortiz, quien resalta la necesidad de enfocar los proyectos científicos desde perspectivas como la social, la económica, la cultural, la política, la académica y la científica, para consolidar comunidades e incluir variables cualitativas en la medición científica. La inconformidad sobre la forma de medir el impacto ya ha sido presentada, pero no se limita a ese punto, sino que la medición de calidad es totalmente segregada y termina siendo un aspecto de segundo interés, lo cual desconoce los procesos y estructuras editoriales, el esfuerzo humano de los editores — quienes destinan más tiempo a su labor del que realmente se asigna y paga-, y la inversión económica institucional en sostener espacios de divulgación de la ciencia.

IV.III. Discusión sobre la política pública de ciencia, tecnología e innovación y el sentido de la investigación

Siempre que se generan procesos de investigación, reflexión y revisión científica se plantean objetivos y se trata de responder a un interrogante personal, profesional, a una problemática práctica-contextual o a la indagación teórica profunda, es decir, a dar respuesta a un para qué y a un sentido del quehacer científico. En este ámbito, los editores no presentan ideas sesgadas sobre lo que se debe investigar y publicar, sino que reconocen la importancia de explorar y avanzar en todas las temáticas propias y conexas de la contabilidad; empero, a su vez recalcan constantemente la necesidad de que la producción académica impacte la sociedad y tenga sentido en la realidad sociocontextual. Se erige entonces la tensión sobre la esencia de la ciencia, la investigación y las publicaciones, pues allí hay posiciones diversas que quizá responden a visiones ontológicas y políticas sobre el significado de la investigación.

El núcleo está en saber si la investigación debe estar desligada o preocupada por el impacto social. Principalmente Alba, Ortiz, Gómez, Sarmiento, Arias y Giraldo presentan argumentos en esa vía, asentando ideas sobre la misión social de la ciencia y la necesidad de no ser funcionalmente ortodoxos y utilitaristas 
Arias, J. D., et al. Aproximaciones contextuales sobre el devenir de las revistas contables colombianas...

sobre la actividad científica universitaria. De esta manera puede indicarse que las publicaciones, por acción u omisión, generan impactos en la sociedad, pero no siempre son impactos conscientes de las necesidades sociales e interesados en transformar las organizaciones, comunidades o instituciones que entretejen la vida socioeconómica.

Es notorio que internacionalmente se fortalecen los espacios de crítica a la hegemonía oligopólica de las grandes casas editoriales comerciales (Emerald, Wiley, Elsevier, Springer, Taylor y Francis, Routledge, SAGE, Inderscience, entre otras) para calificar lo que se denomina 'científico', cuyos criterios favorecen condiciones económicas, geográficas, históricas, políticas, idiomáticas y formas de construcción del conocimiento. ¿Acaso la producción de conocimiento no debe ser pluricultural, validada por comunidades y colectividades diversas e incluyentes? ¿Qué impacto social tienen las publicaciones para el devenir social regional?

\section{IV.IV. Discusión sobre el sentido de la investigación y la interacción} de una comunidad académica (nacional e internacional)

Bajo el manto de las publicaciones científicas en contabilidad, su reconocimiento, su tradición y el respeto por parte de la comunidad académica, persisten proyectos editoriales con limitaciones económicas que edición tras edición forjan un propósito común de mediar la relación entre las ideas originales de autores con su comunidad, a partir de evaluaciones rigurosas y difundir conocimiento con sentido. Al respecto, Camargo presenta diversas tensiones sobre los procesos de financiación de las publicaciones, sus retos y la tendencia internacional de ese particular, que debe ser revisado a fondo por cada institución y revista para actuar en consecuencia del conocimiento abierto financiado por las instituciones editoras o captar recursos a través del cobro a los autores.

A su vez, en algunas latitudes le llaman 'contribución' al impacto de los artículos en su comunidad, pero esta relación implica no solo la agregación funcionalista de ideas a los constructos del saber, sino la pertinencia socio-contextual de las ideas y la retante labor de utilizar las letras para la transformación material y concreta del statu quo. Sobre ello los editores participantes no presentan mayores apuntes, y se intuye que hace parte de los procesos de cualificación y maduración de las publicaciones.

\section{Consideraciones finales}

El devenir de las revistas contables colombianas es incierto a pesar de las constantes cualificaciones de las publicaciones vigentes, para lo cual se demanda atención y apoyo de la comunidad contable nacional y de las instituciones editoras, así como trabajo articulado en red que permita avanzar 
en la discusión de las categorías planteadas y generar acciones conjuntas en beneficio de las dimensiones de calidad e impacto de las revistas y de las discusiones disciplinares de la contabilidad. Igualmente es notorio que las problemáticas de las publicaciones contables no se distancian de aquellas de las ciencias económicas y sociales, que también adolecen por los mismos criterios métricos.

Las políticas públicas de ciencia, tecnología e innovación demuestran su prevalencia en el factor de impacto a través del cálculo del índice h5 como criterio de calidad en la clasificación de las revistas, siguiendo las disposiciones de la OCDE y Scimago. En consecuencia, para Minciencias la citación sigue siendo el único referente de calidad, a pesar de las críticas constantes de diferentes orígenes y las constantes demostraciones que evidencian, lo impertinente de esta medida para el desarrollo social del país, la asimetría entre las revistas nacionales e internacionales y la ventana de posibilidades de manipulación e inflación de cifras.

La posibilidad de tener modelos distintos de medición y el reconocimiento socio-contextual pueden ser más pertinentes para consolidar comunidades académicas y construir disciplinas más plurales y democráticas, donde se ubique a las revistas como los mejores canales de difusión y discusión de las transformaciones de las organizaciones y de la vida social. Los argumentos presentados por los 13 editores participantes deben trascender la lectura y ser discutidos en los cuerpos editoriales e instancias institucionales, buscando acciones que permitan prácticas más legítimas.

Las implicaciones de este debate argumental entre editores deben permitir ampliar el imaginario del sentido de la investigación que comparten comunidades específicas y espera aportar a repensar valores profesionales y prácticas disciplinares del campo contable en relación con las revistas científicas, porque cada vez más se debe comprender que la ciencia contable en Colombia es más que la representación de sus citas.

\section{Referencias bibliográficas}

Adams, J., McVeigh, M., Pendlebury, D. \& Szomszor, M. (2019). Profiles, not metrics. Recuperado de: https://clarivate.com/g/profiles-not-metrics/

Alperin, J. P. y Rozemblum, C. (2017). La reinterpretación de visibilidad y calidad en las nuevas políticas de evaluación de revistas científicas. Revista Interamericana de Bibliotecología, 40(3), 231-241. DOI: https://doi.org/10.17533/udea.rib.v40n3a04

Andrew, J., Cooper, C. \& Gendron, Y. (2020). Editorial. Critical perspectives on accounting and journal rankings: Engaging in counter discourses and practices. Critical perspectives on Accounting.

Arias-Suárez, J. D. (2018). La dinámica antilógica de las publicaciones científicas. Revista Colombiana de Contabilidad, 6(11), 9-12. 
Arias, J. D., et al. Aproximaciones contextuales sobre el devenir de las revistas contables colombianas...

Baldvinsdottir, G., Mitchell, F., \& Norreklit, H. (2010). Issues in the relationship between theory and practice in management accounting. Management Accounting Research, 21(2), 79-82.

Beltrán, J. (2017) Manual de edición académica. Universidad de los Andes y Universidad Nacional de Colombia. Bogotá.

Biagioli, M. \& Lippman, A. (2020). Gaming the Metrics. Misconduct and Manipulation in Academic Research. London. The MIT Press.

Bonner, S. E., Hesford, J. W., Van, d. S., \& Young, S. M. (2006). The most influential journals in academic accounting. Accounting, Organizations \& Society, 31(7), 663-685.

Bruni, A. y Magaudda, P. (2017). Abriendo la caja negra de la investigación académica: evaluación, publicación y perspectivas críticas. Teknokultura, 14(1), 57-65.

Callaway, E. (2016). Publishing elite turns against impact factor. Nature, 535, 210-211.

Camargo, D. A. (2018a). Editorial. Acerca de las razones por las cuales se citan las publicaciones científicas. Revista de Facultad de Ciencias Económicas, 26(2), 5-6. DOI: https://doi.org/10.18359/rfce.3858

Camargo, D. A. (2018b). Financiación del libro en acceso abierto. Periódico El Neogranadino, Edición Especial, 115-116. Recuperado de: https://www.umng.edu.co/academia2

Camargo, D. A. (2019). Acerca del incremento de los Article Processing Charges. Revista Facultad de Ciencias Económicas, 27(2), 7-8. DOI: https://doi.org/10.18359/rfce.4293

Castaño, C. E. (2019). La investigación formativa en programas de contaduría: el caso de la Universidad de Antioquia. Revista Visión Contable, 20, 136 - 154.

Chan, K. C., Seow, G. S., \& Tam, K. (2009). Ranking accounting journals using dissertation citation analysis: A research note. Accounting, Organizations \& Society, 34(6), 875-885.

Chapman, C. S., Hopwood, A. G., \& Shields, M. D. (2007). Handbook of management accounting research. London: Elsevier.

Charum, J. (2004). La Construcción de un Sistema Nacional de Indexación, el Caso de Publindex. Convergencia Revista de Ciencias Sociales, 11(35), 293-309.

De Sousa-Santos, B. (1998). De la mano de Alicia: lo social y lo político en la posmodernidad. Bogotá D.C., Colombia: Universidad de los Andes y Siglo del Hombre.

Erzsébet, D. (2018). How "Publish or Perish" Can Become "Publish and Perish" in the Age of Objective Assessment of Scientific Quality. Systemics, cybernetics and informatics, 16(5), 20-25.

Garrocho, R. C. y Segura, G. A. (2012). La pertinencia social y la investigación científica en la universidad pública mexicana. Revista CIENCIA ergo sum, 19(1): 24-34.

Gómez-Morales, Y. J. (2015). Usos y abusos de la bibliometría. Revista Colombiana de Antropología, 51 (enero-junio), 291-307. Recuperado de: http://www.investigacion. unal.edu.co/seminario2013/.

Gómez-Morales, Y. J. (2018). Abuso de las medidas y medidas abusivas. Crítica al pensamiento bibliométrico hegemónico. Anuario Colombiano de Historia Social y de la Cultura, 45(1), 269-290.

Gómez-Morales, Y. J. (2019). El eterno retorno de lo mismo: Círculos viciosos en busca de una ciencia nacional independiente. Revista Colombiana de Sociología, 42(2), 357-364. DOI: https://doi.org/10.15446/rcs.v42n2.82100 
Gómez-Villegas, M. (2012). Editorial. Revistas académicas en contabilidad: la búsqueda de sentido contextual. Revista Facultad de Ciencias Económicas, 20(2), 9-13.

Gómez-Villegas, M. (2013). El reconocimiento contextual y el aprendizaje de las publicaciones internacionales en contabilidad. Cuadernos de Contabilidad, 14(34), 273284.

Gómez-Zapata, Y. (2019). ¿Cómo y para qué nos miden? Crítica reflexiva sobre el proceso de medición Publindex-Colciencias para revistas científicas en Colombia. En-Contexto, 7(11), 35-37.

Griffith, D., Tamer Cavusgil, S. \& Xu, S. (2008) Emerging themes in international business research. J Int Bus Stud 39, 1220-1235. DOI: https://doi.org/10.1057/palgrave. jibs. 840041

Guédon, J-C. (2011). El acceso abierto y la división entre ciencia "principal" y "periférica". Crítica y Emancipación, 3(6), 135-180.

Hopwood, A. G. (2002). If only there were simple solutions, but there aren't: some relections on Zimmerman's critique of empirical management accounting research. European Accounting Research, 11(4), 777-785.

Humphrey, C., \& Gendron, Y. (2015). What is going on? The sustainability of accounting academia. Critical Perspectives on Accounting, 26, 47-66. DOI: https://doi.org/10.1016/J. CPA.2014.09.008

Ittner, C. D., \& Larcker, D. F. (2001). Assessing empirical research in managerial accounting: a value-based management perspective. Journal of Accounting and Economics, 32(1-3), 349-410.

Ittner, C. D., \& Larcker, D. F. (2002). Empirical managerial accounting research: are we just describing management consulting practice? European Accounting Research, 11(4), 787-794.

Johnson, R. (2019). From coalition to commons: Plan $S$ and the future of scholarly communication. Insights the UKSG journal, 32(1), 5. DOI: http://doi.org/10.1629/uksg.453

Khoo, S.Y.-S. (2019). Article Processing Charge hyperinflation and price insensitivity: an open access sequel to the serials crisis. LIBER Quarterly, 29(1), 1-18. DOI: http://oi. org/10.18352/lq. 10280

León, E. F. (2009). Delineando complejos cognitivos: la producción científica de las disciplinas económicas en América Latina. Contaduría Universidad de Antioquia, 54, 79-115.

León, E. F. (2015). Carta al editor contable. Contaduría, 67, 17-20.

López Cerezo, J. (2001). Ciencia, Tecnología y Sociedad: el estado de la cuestión en Europa y Estados Unidos. Revista Iberoamericana de Educación. 18: Monográfico: Ciencia, Tecnología y Sociedad ante la Educación. OEI.

Luft, J., \& Shields, M. D. (2002). Zimmerman's contentious conjectures: describing the present and prescribing the future of empirical management accounting research. European Accounting Review, 11(4), 795-805.

Lukka, K. (2010). The roles and effects of paradigms in accounting research. Management Accounting Research, 21(2), 110-115.

Lukka, K., \& Mouritsen,J. (2002). Homogeneity or heterogeneity of research in management accounting? European Accounting Review, 11(4), 805-811. 
Arias, J. D., et al. Aproximaciones contextuales sobre el devenir de las revistas contables colombianas...

Macías, H. A. (2012). Las revistas académicas como plataforma para la construcción de conocimiento contable. Revista Facultad de Ciencias Económicas, 20(2), 5-9.

Macías, H. A. (2013). Debate sobre el presente y el futuro de las revistas contables colombianas: acuerdos, desacuerdos y retos. Cuadernos de Contabilidad, 14(34), 265-271.

Macías, H. (2017). Editorial. El sentido de publicar en revistas Scopus: el caso de los autores colombianos de las áreas de negocios, administración y contaduría. Science of human action, 2(1), 10-18.

Macías, H. A. (2018). Introducción a la investigación contable en Brasil. Revista Activos. 16(30), 155-186.

Macías, H. (2019). España y Venezuela como impulsores de la academia contable colombiana. Revista Visión Contable, 20, 8-20. https://doi.org/10.24142/rvc.n20a1

Macías, H. A. (2020). Investigación contable en Colombia: oportunidades concretas para publicar en revistas Scopus. En: M. Aguilera-Prado \& M. Rincón-Moreno, Temas y métodos de investigación en negocios, administración, mercadeo y contabilidad. Pp. 27-49. Bogotá: Uniagustiniana. Versión Researchgate.

Macías, H., Gómez, M. y León, E. F. (2012). Editorial. Revista Facultad de Ciencias Económicas, 20(2), 5-17.

Macías, H. A., Alzate, S., Bautista, J. A., Morales, Abel., Castaño, C. E., Ceballos, R., Cortés, J. H., García, C. E., Gómez, Y. Ortiz, J. J., Quijano, O., Rodríguez, G. I., Rueda, G. y Sarmiento, H. J. (2014). El futuro de las revistas contables colombianas: un debate polifónico. Cuadernos de Contabilidad, 15(37), 261-278.

Malaver, D. S. (2018). Editorial. ¿Publicar o perecer? Una reflexión crítica sobre el viraje del sentido de las publicaciones académicas de medios a fines. Revista Colombiana de Contabilidad, 6(12), 9-16.

Maldonado, C, y Pérez-Acosta, A (2018). Una reflexión crítica sobre la cultura de rankings e indicadores. Avances en Psicología Latinoamericana, 36(3), 431-441.

Malmi, T., \& Granlund, M. (2009). In search of management accounting theory. The European Accounting Review, 18(3), 597-620.

Merchant, K.A. (2010). Paradigms in accounting research: a view from North America. Management Accounting Research, 21(2), 116-120.

Meyer, M., Waldkirch, R. W., Duscher, I., \& Just, A. (2018). Drivers of citations: An analysis of publications in "top" accounting journals. Critical Perspectives on Accounting, 51, 24-46. DOI: https://doi.org/10.1016/j.cpa.2017.07.001

Modell, S. (2010). Bridging the paradigm divide in management accounting research: the role of mixed methods approaches. Management Accounting Research, 21(2), 124-129.

Molas-Gallart, J., \& Ràfols, I. (2018). Why bibliometric indicators break down: Unstable parameters, incorrect models and irrelevant properties. BiD: Textos Universitaris de Biblioteconomia i Documentació, 40 (juny). DOI: https://doi.org/10.1344/BiD2018.40.23

Ortiz, J. J. (2019). La perspectiva crítica de la investigación y la gestión del conocimiento en las universidades colombianas. Criterio Libre, 17(30), 15-45. DOI: https://doi. org/10.18041/1900-0642/criteriolibre.2019v17n30.5750 
Ortiz, J. J., Bermúdez, A., Gómez, M., León, E. F., Suárez, J., Camargo, D., y Moncayo, E. (2014). Panel de editores. Criterio Libre, 12(20), 293-311. DOI: https://doi. org/10.18041/1900-0642/criteriolibre.2014v12n20.245

Ortiz, J. J. (2017). Modelo de gestión del conocimiento para las IES colombianas. Bogotá: Editorial Universidad Libre.

Palea, V. (2017). Whither accounting research? A European view. Critical Perspectives on Accounting, 42, 59-73. DOI: https://doi.org/10.1016/j.cpa.2016.03.002

Patiño, R. A., Melgarejo, Z. A. y Valero, G. M. (2018). Percepción de los egresados contables sobre la investigación formativa. Revista Activos. 16(30), 101 - 125.

Ripoll, V. (2012). Relación Universidad - Empresa y la Transferencia de Conocimiento Utilidad para la Investigación en Control de Gestión. Confin Habana, 2, 9-16.

Rodríguez, E., Naranjo, S. y González, D. L. (2015). Publindex: More Than a Simple Indexing Process. El Ágora U.S.B., 15(1), 29-41. Recuperado de: http://www.scielo.org.co/pdf/ agor/v15n1/v15n1a02.pdf

Rojas-Rojas, W. (2017). Asimilación y rupturas de la educación de la contaduría pública: Desde el sur y para el sur. Contaduría Universidad de Antioquia, 71, 85-101. Recuperado de: https://aprendeenlinea.udea.edu.co/revistas/index.php/cont/article/ view/332822/20788831

Rueda, G. (2009). Orígenes de la producción académica contable. Cuadernos de Contabilidad, $10(26)$.

Rueda, G. (2012). El sentido de buscar que Cuadernos de Contabilidad sea en el futuro una revista incluida en ISI. Cuadernos de Contabilidad, 13 (32), 10-14.

Sánchez, L. M. (2019). Editorial. Las redes para la producción de conocimiento y su impacto editorial. Visión Contable, 19, 5-7.

Sarmiento, H. J. (2018). Editorial. La incertidumbre por destino. Teuken Bidikay, 9(12), 11-17.

Science Europe (2018). 'Plan S: Making Full and Immediate Open Access a Reality'. Recupeardo de: https://www.coalition-s.org/

Vaivio, J., \& Sirén, A. (2010). Insights into method triangulation and "paradigms" in interpretive management accounting research. Management Accounting Research, 21(2), 130-141.

Van Leeuwen, T. (2012). Discussing some basic critique on Journal Impact Factors: Revision of earlier comments. Scientometrics, 92(2), 443-455. DOI: https://doi.org/10.1007/ s11192-012-0677-x

Vega-Cantor, R. (2015). La Universidad de la Ignorancia: Capitalismo académico y mercantilización de la educación superior. (1era ed.). Bogotá D.C.: Ocean Sur.

Wakefield, R. (2008). Networks of accounting research: A citation-based structural and network analysis. British Accounting Review, 40(3), 228-244. DOI: https://doi. org/10.1016/j.bar.2008.03.001

Zimmerman, J. L. (2001). Conjectures regarding empirical managerial accounting research. Journal of Accounting and Economics, 32(1), 4, 11-427. 